ver FC, White TJ, eds. Diagnostic Molecular Microbiology: Principles And Applications. Washington, DC: American Society for Microbiology; 1993: 563-572.

6. Tenover FC, Arbeit RD, Goering RV, et al. Interpreting chromosomal restriction patterns produced by pulsed-field gel electrophoresis: criteria for bacteria strain typing. J Clin Microbiol 1995; 33:2233-2239.

7. Pitt TL, Gaston MA. Pseudobacteraemia and ESR bottles. J Hosp Infect $1982 ; 3: 395-397$.

8. Emmanuel FX, Aucken H, Watt B, et al. False-positive blood-cultures from contaminated ESR tubes. Lancet 1993; 341:111-112.

9. San Juan R, Marin-Rabadan P, Marin M, Hermamgomez S, RodriguezCreixems M, Bouza E. Pseudobacteremia outbreak in pediatric patients due to cross-contamination with erythrocyte sedimentation rate tubes. In: Programs and abstracts of the 39th International Conference on Antimicrobial Agents and Chemotherapy (San Francisco). 1999: 652. Abstract 2086.

10. Hoffman PC, Arnow PM, Goldmann DA, Parrott PL, Stamm WE, McGowan JE Jr. False-positive blood cultures. Association with nonsterile blood collection tubes. JAMA 1976; 236:2073-2075.

11. McNeil MM, Davis BJ, Anderson RL, Martone WJ, Solomon SL. Mechanism of cross contamination of blood culture bottles in outbreaks of pseudobacteremia associated with nonsterile blood collection tubes. $J$ Clin Microbiol 1985; 22:23-25.

\section{A Controlled Study of Legionella Concentrations in Water from Faucets with Aerators or Laminar Water Flow Devices}

TO THE EDITOR-Water aerators and laminar water flow devices are used to decrease water flow by forcing air through faucets. Washing with the air and water combination feels the same as it does with constant water flow, but the combination dramatically reduces water consumption by as much as $60 \% .^{1,2}$ The use of these items is recommended by the US Environmental Protection Agency for water conservation in various locations, including office buildings, hotels, and hospitals.

However, faucet aerators have been colonized by waterborne pathogens, and these pathogens have been epidemiologically linked to hospital-acquired infections. ${ }^{3-7}$ Removal of aerators from faucets in the healthcare setting has been an accepted infection control practice for decades, and guidelines from the Centers for Disease Control and Prevention, the Healthcare Infection Control Practices Advisory Committee, ${ }^{8}$ the American Society of Heating, Refrigerating, and Air Conditioning Engineers, ${ }^{9}$ and others ${ }^{10}$ recommend removal of aerators or laminar water flow devices to prevent colonization by Legionella species and other waterborne pathogens. Specific recommendations have been made, especially for areas housing high-risk patients, according to which aerators either should not be used, ${ }^{10}$ or if used, they should be designed with radially and vertically arranged lamellae (which do not lead to the collection of sediment or water stagnation) and cleaned regularly.
Because hospitals in Taiwan have been experiencing water shortages during the drought season, during which patient care may be compromised, we conducted a study to test the hypothesis that installation of aerators and laminar water flow devices would actually promote the growth of Legionella species in a healthcare facility.

A model plumbing system (Figure) was built in a hospital with history of colonization by Legionella species and gramnegative bacteria. The system consisted of 3 sets of duplicate faucets arranged in parallel: 2 faucets with aerators (A1205; Tien Kuang), 2 faucets with laminar water flow devices (LF2043; Tien Kuang), and 2 faucets without any aerating attachment (control faucets). The entire model system was steam autoclaved before use. The model was then attached to a water pipe with an existing water outlet on top of a laboratory basin. When the water outlet was used at random times, water also flowed uniformly through all 6 faucets. Water samples of $500 \mathrm{~mL}$ were collected from each faucet and concentrated to $5 \mathrm{~mL}$ by use of a $0.22 \mu \mathrm{m}$-pore filter. After removal of the aerators or laminar water flow devices, a sterile swab (BBL CultureSwab; Becton Dickinson) with transportation media was inserted into each faucet outlet and rotated against the interior surface 2 times clockwise and 2 times up and down to dislodge sediment in the faucet. Each swab was vortexed vigorously in $2 \mathrm{~mL}$ of sterile deionized water to resuspend the sediment from the swab into the aliquot of water. One hundred $\mu \mathrm{L}$ from each acid-treated sample was directly inoculated onto buffered charcoal yeast extract culture media and buffered charcoal yeast extract selective media containing dyes, glycine, vancomycin, and polymyxin B. Culture media were incubated at $37^{\circ} \mathrm{C}$ in a humidified atmosphere for 3-7 days. Paired $t$-tests were performed with Excel software (Microsoft).

During the 27 -week study period, a total of 102 biofilm

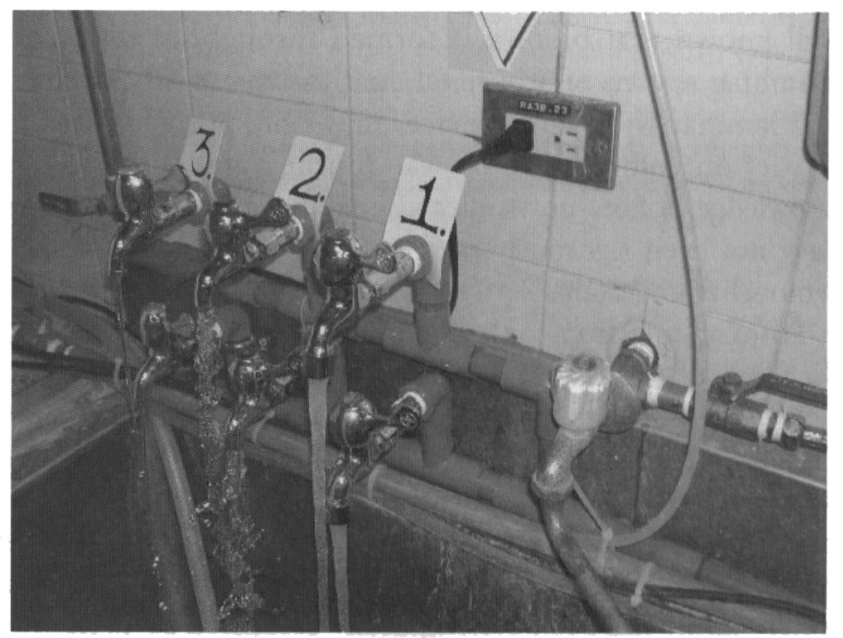

FIGURE. Experimental set up of the model plumbing system (1, faucets with aerators; 2 , control faucets; 3 , faucets with laminar water flow devices). 
and water samples were collected from control faucets, faucets with aerators, and faucets with laminar water flow devices. The mean concentration of Legionella species in water samples collected from control faucets was $3,529 \mathrm{cfu} / \mathrm{L}$. In faucets with aerators, the mean concentration was $2,412 \mathrm{cfu} / \mathrm{L}$; in faucets with laminar water flow devices, the mean concentration was $5,912 \mathrm{cfu} / \mathrm{L}$. Water samples from faucets with aerators yielded the lowest concentration of Legionella species. No significant difference was found in the concentration of Legionella species in water samples from control faucets, compared with samples from faucets with aerators $(P=.53)$, and no significant difference was found when samples from control faucets were compared with samples from faucets with laminar water flow devices $(P=.45)$. The mean concentration of Legionella species from biofilm samples collected from control faucets was $530 \mathrm{cfu} / \mathrm{L}$, the mean concentration in faucets with aerators was $515 \mathrm{cfu} / \mathrm{L}$, and the mean concentration in faucets with laminar water flow devices was $647 \mathrm{cfu} / \mathrm{L}$. Similarly, no significant difference was found in the concentration of Legionella species when biofilm samples for control faucets and faucets with aerators were compared $(P=.56)$ or when samples from control faucets and faucets with laminar water flow devices were compared $(P=0.38)$. Legionella species were observed in faucets with aerators, faucets without aerators, and faucets with laminar water flow devices, and no significant difference was found in the bacterial concentration in either water or biofilm samples from the 3 types of faucet. The volume of water saved was also tested by measuring the flow rate of water from the 3 types of faucet. The mean flow rate was $6.0 \mathrm{~L} / \mathrm{min}$ for faucets with aerators and $1.2 \mathrm{~L} / \mathrm{min}$ for faucets with laminar water flow devices, compared with $11.0 \mathrm{~L} / \mathrm{min}$ for the control faucets.

It is conceptually possible that aerators and laminar water flow devices obstruct the water flow, thus promoting the growth and amplification of microorganisms inside faucets with aerators and laminar water flow devices. However, it is well known that biofilm is formed throughout the water plumbing system of a hospital, and the removal of aerators and laminar water flow devices may not have a significant impact on colonization by waterborne pathogens. To our knowledge, follow-up studies after removal of these devices have not been rigorously performed, so the efficacy of such removal is uncertain.

From an infection control point of view, our study showed that lack of aerators or laminar water flow devices did not reduce the concentration of Legionella species in the faucets. Legionella could still be detected in faucets with and faucets without aerators. Thus, removal of or routine cleaning of contaminated faucet aerators or laminar water flow devices may not prevent hospital-acquired infections if the hospital's water supply has been systematically colonized by Legionella species.
In conclusion, we were unable to confirm the generally accepted perception that installation of aerators and laminar water flow devices promote the bacterial amplification of $L e$ gionella species in water and biofilm samples. The use of aerators and laminar water flow devices was effective in reducing water usage. A large-scale study is needed to validate our finding so that the risk-benefit ratio of using these devices can be accurately estimated.

\section{ACKNOWLEDGMENTS}

Potential conflicts of interest. All authors report no conflicts of interest relevant to this article.

Wen-Kuei Huang, MS; Yusen Eason Lin, PhD, MBA

From the Reference Medical Laboratory, Taichung (W.-K.H.), and the National Kaohsiung Normal University, Kaohsiung (Y.E.L), Taiwan.

Address reprint requests to Yusen $\mathrm{E}$. Lin, $\mathrm{PhD}, \mathrm{MBA}$, Graduate Institute of Environmental Education, National Kaohsiung Normal University, 62 Shen-chong Rd., Yanchao, Kaohsiung, Taiwan 824 (easonlin@nknucc.nknu .edu.tw).

Infect Control Hosp Epidemiol 2007; 28:765-766

(C) 2007 by The Society for Healthcare Epidemiology of America. All rights reserved. 0899-823X/2007/2806-0029\$15.00. DOI: $10.1086 / 519699$

\section{REFERENCES}

1. Jensen R. Indoor water conservation. Texas Water Resources 1991; 17:1.

2. US Environmental Protection Agency. How to conserve water and use it effectively. In: Cleaner Water Through Conservation (EPA 841-B-95002). US Environmental Protection Agency; 1995. Available at: http:// www.epa.gov/nps/chap3.html. Accesses on August 30, 2006.

3. Wilson MG, Nelson RC, Phillips LH, Boak RA. New source of Pseudomonas aeruginosa in a nursery. JAMA 1961; 175:1146-1148.

4. Fierer J, Taylor PM, Gezon HM. Pseudomonas aeruginosa epidemic traced to delivery-room resuscitators. $N$ Engl J Med 1967; 276:991-996.

5. Ciesielski CA, Blaser MJ, Wang WL. Role of stagnation and obstruction of water flow in isolation of Legionella pneumophila from hospital plumbing. Appl Environ Microbiol 1984; 48:984-987.

6. Weber DJ, Rutala WA, Blanchet CN, Jordan M, Gergen MF. Faucet aerators: a source of patient colonization with Stenotrophomonas maltophilia. Am I Infect Control 1999; 27:59-63.

7. Kappstein I, Grundmann H, Hauer T, Niemeyer C. Aerators as a reservoir of Acinetobacter junit: an outbreak of bacteremia in pediatric oncology patients. J Hosp Infect 2000; 44:27-30.

8. Sehulster L, Chin RY, Centers for Disease Control and Prevention, Healthcare Infection Control Practices Advisory Committee. Guidelines for environmental infection control in health-care facilities: recommendations of CDC and the Healthcare Infection Control Practices Advisory Committee (HICPAC). MMWR Recomm Rep 2003;52(RR-10):1-42.

9. American Society of Heating, Refrigerating, and Air-Conditioning Engineers. ASHRAE Guideline 12-2000: Minimizing the Risk of Legionellosis Associated With Building Water Systems. Atlanta, GA: American Society of Heating, Refrigerating, and Air-Conditioning Engineers; 2000.

10. Freije MA, Barbaree JM. Legionellae Control in Health Care Facilities: $A$ Guide for Minimizing Risk. Indianapolis: HC Information Resources; 1996. 